\title{
Workability maintenance of water-reducing admixtures in high-performance pastes produced with different types of Portland cement
}

\author{
Paulo Ricardo de Matos ${ }^{1}$, Rafael Dors Sakata ${ }^{1}$ Maiara Foiato ${ }^{1,2}$, \\ Wellington Longuini Repette ${ }^{1}$, Philippe Jean Paul Gleize ${ }^{1}$.
}

\author{
${ }^{1}$ Universidade Federal de Santa Catarina (UFSC), Departamento de Engenharia Civil, Rua João Pio Duarte Silva, 205, \\ CEP: 88037-000, Florianópolis, SC, Brasil. \\ ${ }^{2}$ Universidade do Oeste de Santa Catarina (UNOESC), Departamento de Engenharia Civil, Rua Getúlio \\ Vargas, 2125, CEP: 89600-000, Joaçaba, SC, Brasil. \\ e-mail: paulorm.matos@gmail.com,rafaelsakata@gmail.com, maiarafoiato@yahoo.com.br, \\ wellington.repette@gmail.com,p.gleize@ufsc.br.
}

\begin{abstract}
This work evaluated the efficiency and workability manteinance of a polyfunctional (lignosulfonate-based) and a superplasticizer (polycarboxylate-based) admixture in high-performance pastes (water/cement ratios of $0.30,0.33$ and 0.36 ) produced with two types of Portland cement (one pozzolanic and one high early strength). The workability of the pastes was evaluated by the mini slump test immediately after mixing, and after 20 and 40 minutes. Furthermore, the mechanical strength of pastes with fixed w/c ratio (0.36) and mini slump $(130 \mathrm{~mm})$, produced with the different combinations of cements and admixtures, was evaluated. The results showed that the $\mathrm{CP}$ IV+lignosulfonate and $\mathrm{CP}$ V-ARI+polycarboxylate mixes presented the best workability maintenance over time. The pastes produced with CP V-ARI presented 28-day strengths about $22 \%$ higher than those produced with CP IV, for both admixtures. In turn, the lignosulfonate-containing pastes showed strengths about $10 \%$ higher than those produced with the polycarboxylate-based admixture. Overall, it was possible to obtain the same workability for high-performance Portland cement pastes produced with both admixtures and cements; however, the workability mantainance and mechanical strength highly depends on the combination of cement and admixture used.
\end{abstract}

Keywords: Cement paste; Workability maintenance; Polyfunctional; Superplasticizers; Mini slump.

\section{INTRODUCTION}

Modern concrete contains components with very specific characteristics that give particular properties to the mix, as well as chemical admixtures that have even more specific effects [1]. The use of admixtures in cementitious materials enables the production of mixes for a wide variety of applications due to the advantages they provide in both fresh and hardened state [2]. Water-reducing admixtures are also known as plasticizers and superplasticizers, and act as cement particle dispersants. These products are used in concrete to increase its flowability without changing the mix composition, or by reducing the water consumption while maintaining the workability, therefore reducing the water/cement (w/c) ratio and improving the mechanical strength and durability. The main difference between plasticizers and superplasticizers is in performance: while a plasticizer can decrease the mix water by $5-12 \%$, the superplasticizer is able to reduce the amount of water by 20-30\% [3].

In concrete, the hydrating cement particles tend to flocculate due to the polarity of the water molecules and the Van der Waals attracting forces between the particles, which are electrostatic forces between opposite surface charge regions of cement. Therefore, the flocculation reduces the specific surface area of cement available for hydration. Since hydration begins immediately after the contact of cement with water, the cement particles must be deflocculated and dispersed to achieve an homogeneous hydration [4]. Thus, the main function of water-reducing admixtures is to disperse the cement particles, thus releasing the entrapped water between the grains, which consequently increases the flowability of the mix [5].

Lignosulfonate is the most widely used plasticizer, obtained from lignin, which is a liquid waste from the cellulose extraction process. As for the superplasticizers, the polycarboxylate-ether (PCE) admixture stands out, which has properties determined by molecular parameters such as molecular chain length and the 
frequency, size and composition of side chains attached to the main chain. PCE superplasticizers are known to provide better workability maintenance compared to naphthalene- and melamine-based superplasticizers [6]. In addition, PCE provides greater reductions in water content of concrete compared to melamine or naphthalene superplasticizers [7].

The workability loss of cement-based materials occurs rapidly in the presence of water-reducing admixtures. After the cement reactions start, large amounts of hydrated products are formed, such as ettringite. These products "capture" (i.e. adsorb) the admixture molecules present in the system. Thus, several factors related to cement composition and reactivity - as well as to the system itself - affect the cement-admixture interactions, such as ambient temperature, water $\mathrm{pH}$, cement fineness, and cement composition (mainly C3A, $\mathrm{SO}_{3}$ and alkali contents) [8-11]. Therefore, the cement-admixture interactions affect not only the initial dispersing ability of the water reducer, but also its flowability maintenance capacity. Finally, the admixture's dispersing mechanism plays an important role on mix flowability maintenance: for instance, steric repulsion (which is the main dispersing mechanism of PCE) tends to last longer than electrostatic repulsion (plasticizer's dispersing mechanism) [2].

The frequency of incompatibility problems has increased with the use of superplasticizers in highperformance concrete, which uses low w/c (water/binder) ratios. In such cases, it is no longer possible to solve the problem by removing the superplasticizer from the mixture and this situation is not applied to any type of cement and superplasticizer. Thus, much research has been carried out to try to understand and solve these incompatibility problems [1]. Among the factors, studies have demonstrated the crucial role of both nature and dosage of added calcium sulphate (i.e. gypsum) to control the Portland cement setting, since it controls the rate of dissolution of the cement, which governs the rheology of plasticizer-containing cementitious systems [12]. In addition, C3A content is a determining factor in the cement-admixture compatibility [13]. In this context, the use of cements with mineral admixtures incorporation may be an interesting solution to reduce the overall contents of gypsum and $\mathrm{C} 3 \mathrm{~A}$, thus preventing incompatibility issues. In fact, ALONSO et al. [7] found that PCE molecules may adsorb and disperse fly ash, limestone and slag particles, thus reducing the contents of gypsum and $\mathrm{C} 3 \mathrm{~A}$ while still maintaining the dispersing ability of the system.

This work investigated the workability maintenance of two water reducers (a lignosulfonate-based and a polycarboxylate-based) in high-performance pastes produced with two types of Portland cement (CP IV and CP V - ARI). For this, pastes with w/c ratios of $0.30,0.33$ and 0.36 were produced with each combination of admixture and cement. The workability was evaluated through the mini slump test up to 40 minutes after mixing. Furthermore, the compressive strength of the pastes with w/c ratio of 0.36 and equivalent mini slump spread $(130 \mathrm{~mm})$ were evaluated at 28 days.

\section{MATERIALS AND METHODS}

\subsection{Materials}

Two types of cement were used: a Portland-fly ash cement (CP IV) and high early strength Portland cement (CP V-ARI), both standardized by NBR 16697 [14]. The particle size distributions of the cements are shown in Figure 1. Table 1 presents the physical and chemical characteristics of the cements, according to the manufacturer. Despite CP V-ARI being classified as high early strength, CP IV showed higher specific surface area, probably because the presence of pozzolanic material in the latter (about $26 \%$, according to Table 1) requires a greater fineness to increase its reactivity.

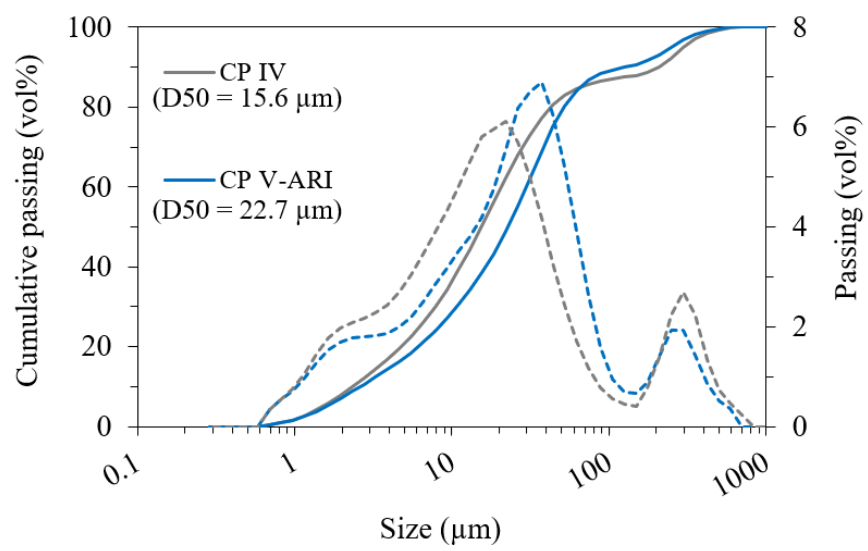

Figure 1. Particle size distribution of the cements used. Note: cumulative passing in full lines and passing in dashed lines. 
Table 1. Physical and chemical characteristics of the cements.

\begin{tabular}{lcc}
\hline Property & CP IV & CP V-ARI \\
\hline Blaine fineness $\left(\mathrm{cm}^{2} / \mathrm{g}\right)$ & 4287 & 4061 \\
Density $\left(\mathrm{g} / \mathrm{cm}^{3}\right)$ & 2.83 & 3.12 \\
Setting time - start (hour:minute) & $03: 40$ & $02: 43$ \\
Setting time - end (hour:minute) & $04: 23$ & $03: 21$ \\
1-day compressive strength (MPa) & 14.6 & 22.2 \\
3-day compressive strength (MPa) & 27.3 & 36.4 \\
7-day compressive strength (MPa) & 33.7 & 42.1 \\
28-day compressive strength (MPa) & 44.7 & 50.2 \\
Insoluble residue (wt\%) & 25.83 & 0.74 \\
Loss on ignition (wt\%) & 3.43 & 3.08 \\
\hline
\end{tabular}

Two water-reducing admixtures were used: a polyfunctional and a superplasticizer, both from the same manufacturer (GCP). The polyfunctional had a lignosulfonate chemical base, while the superplasticizer used had a polycarboxylate chemical base. The physical and chemical characteristics of the admixtures provided by the manufacturer are presented in Table 2 .

Table 2. Physical and chemical characteristics of the cements.

\begin{tabular}{lcc}
\hline Property & Polyfunctional & Superplasticizer \\
\hline Chemical base & Lignosulfonate & Polycarboxylate \\
Solid content $(\mathrm{wt} \%)$ & 36.9 & 49.0 \\
Specific gravity $\left(\mathrm{g} / \mathrm{cm}^{3}\right)$ & $1.20 \pm 0.2$ & $1.10 \pm 0.2$ \\
$\mathrm{pH}$ & $7.5 \pm 1.0$ & $5.5 \pm 1.0$ \\
Recommended content (\% over binder mass) & $0.3-1.0$ & $0.3-2.0$ \\
\hline
\end{tabular}

\subsection{Mix composition and sample preparation}

In this work, pastes with water/cement (w/c) ratios of $0.30,0.33$ and 0.36 were produced. These compositions allowed for the production of flowable and stable pastes with the incorporation of both water reducers. The production of pastes with higher w/c ratios would result in bleeding (especially for those containing the superplasticizer), while lower w/c ratios would result in pastes with low flowability (especially when using the polyfunctional). For each combination of cement, admixture and w/c, three admixture contents were tested, totalling 36 mixes. The pastes were prepared in a planetary mixer with nominal capacity of 5 litters. Initially, all the cement was added to the mixer container. Then, the mixer was turned on at low speed (impeller rotation at $140 \mathrm{rpm}$ and planetary motion at $62 \mathrm{rpm}$ ) and the water was gradually added over 90 seconds. After adding all the water, the mixer was turned off and the material that eventually settled on the paddle and edges was reincorporated into the mixture. Subsequently, the admixture (previously weighed) was added to the paste and the mixer was turned on again at low speed for 60 seconds. Finally, the mixer was turned on at high speed (impeller rotation at $285 \mathrm{rpm}$ and planetary motion at $125 \mathrm{rpm}$ ) for 30 seconds.

\subsection{Testing methods}

The workability of the pastes was evaluated by the mini slump test (or Kantro's cone test) [15]. This apparatus consists of a cone mold with openings of approximately 20 and $40 \mathrm{~mm}$, and a height of approximately $60 \mathrm{~mm}$. The test consists of filling the cone mold with paste and then lifting it. At the end of the paste spreading, two diameter measurements are recorded (at the greatest spread and perpendicularly to that), and the average of these two measurements is taken as the test result.

To evaluate the workability loss over time, immediately after the first mini slump test (referred to as "5 min"), the pastes were stored in sealed plastic containers, and the test was repeated 20 and 40 minutes after the first contact between the water and the dry materials. 
Furthermore, the effect of the water reducer type and content on the mechanical strength of the pastes was evaluated. For this, pastes with w/c ratio of 0.36 were produced, and admixture content was adjusted to achieve a mini slump spread of $130 \pm 10 \mathrm{~mm}$ for all the samples. This w/c ratio would lead to lower water reducer consumptions, thus avoiding any negative effect caused by overdosing the admixtures (for instance, excessive delays in the hydration). Then, three cylindrical specimens of $50 \mathrm{~mm}$ in diameter and $100 \mathrm{~mm}$ in high were cast and tested for compression at 28 days according to NBR 7215 [16]. In this step, the volatile fractions of the admixtures were discounted from the water content of the pastes. Since the water reducer amount varied according to its dispersion ability, such value ranged from 0.20 to $3.00 \%$ by weight of cement (seen in Figure 4). Thus, the difference in the water content present in the admixtures may affect the strength results.

\section{RESULTS AND DISCUSSION}

\subsection{Fresh state}

Figure 2 shows the mini slump spread as a function of time and w/c, for the lignosulfonate mixes, respectively at (a) and (b) for CP IV and CP V-ARI. The admixture contents are presented in \% by weight of cement. It can be noted in Figure $2 \mathrm{a}$ that the mini slump generally reduced over time. However, for high levels of admixture (2.50-3.00\%), there was a maintenance or even an increase of spreading. Very high dosages of water reducers may cause the instability of the mixture, manifested by bleeding [11], a fact that has been verified in some mixtures. The same behavior was observed in CP V-ARI cement paste, shown in Figure $2 \mathrm{~b}$. It is worth noting that it was necessary to use a lower admixture content $(1.00 \%)$ for mixtures with w/c of 0.36 . This is due to the fact that adsorption of the admixture dispersing molecules occurs more sharply in mixtures with higher w/c ratios, since these mixes have greater amounts of water available [17]. Figure 3 shows the mini slump spread as a function of time and w/c, for the polycarboxylate-based admixture, respectively at (a) and (b) for CP IV and CP V-ARI. For this type of admixture, there was a decrease in workability over time regardless the cement type, w/c and the employed admixture content.

The mixes that presented the best workability maintenance were those produced with CP IV and lignosulfonate (Figure 2a) and with CP V-ARI and polycarboxylate (Figure 3b). The efficiency of the admixture is related to the reactivity of the binder particles (i.e. the fineness and composition of the cement): ettringite needles formed in the initial hydration reactions adsorb part of the admixture molecules, reducing the admixture's dispersing effect $[11,12]$. In turn, the presence of pozzolanic material in CP IV reduces the overall content of C3A, forming lower ettringite contents within the first minutes of hydration [18]. This reduces such ettringite-admixture adsorption, apparently increasing the workability maintenance for the lignosulfonate. As for PCE superplasticizers, these molecules tend to have greater affinity with calcium-containing particles, such as Portland cement clinker [19]. Since CP V-ARI has low mineral admixture incorporation (about 5\%, compared to about $26 \%$ for CP IV), the higher amount of clinker in this cement may result in a greater compatibility (and therefore in a higher workability maintenance) for the CP V-ARI + polycarboxylate system. Therefore, these results indicate that compatibility of the water reducer with cement is a major factor for a good workability performance, in line with the literature reports. 
CP IV - LIGNOSULFONATE

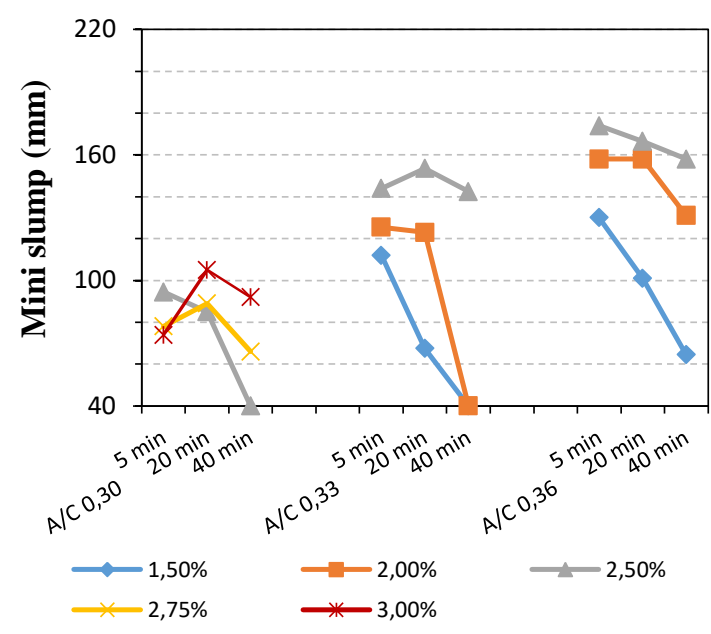

(a)
CP V-ARI - LIGNOSULFONATE

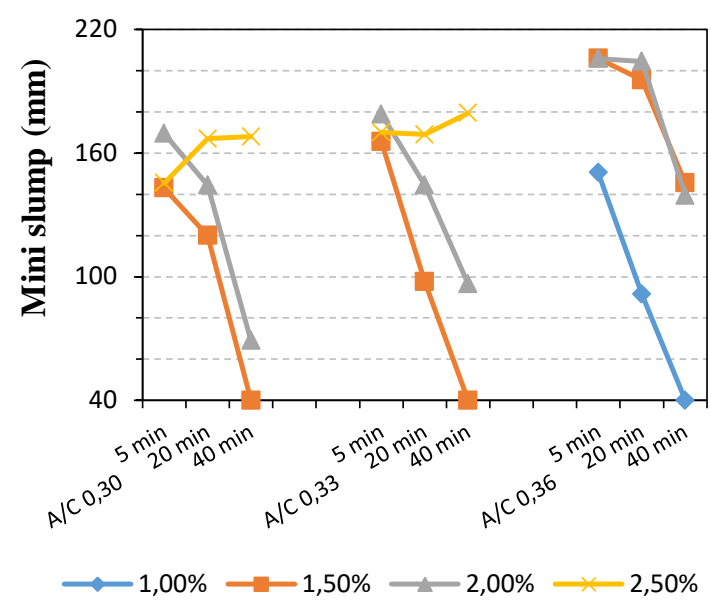

(b)

Figure 2: Mini slump test results over time for the pastes produced with lignosulfonate. (a) CP IV; (b) CPV-ARI.

\section{CP IV - POLYCARBOXYLATE}

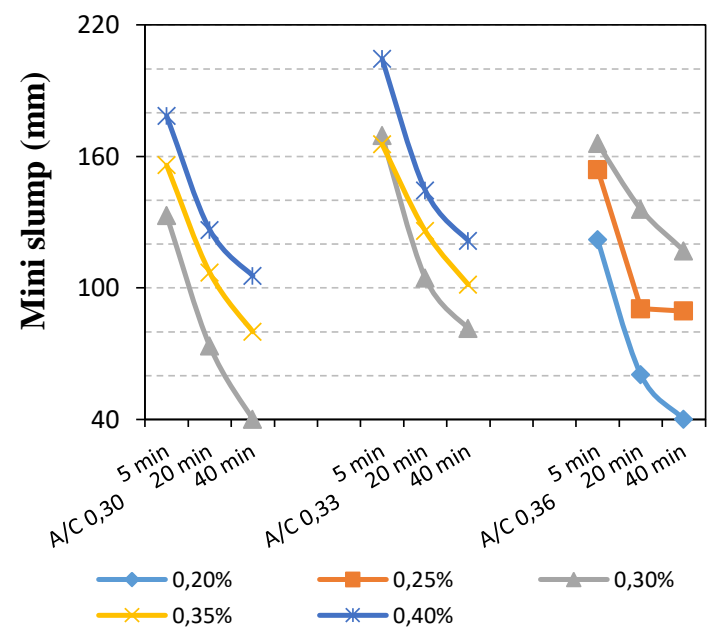

(a)

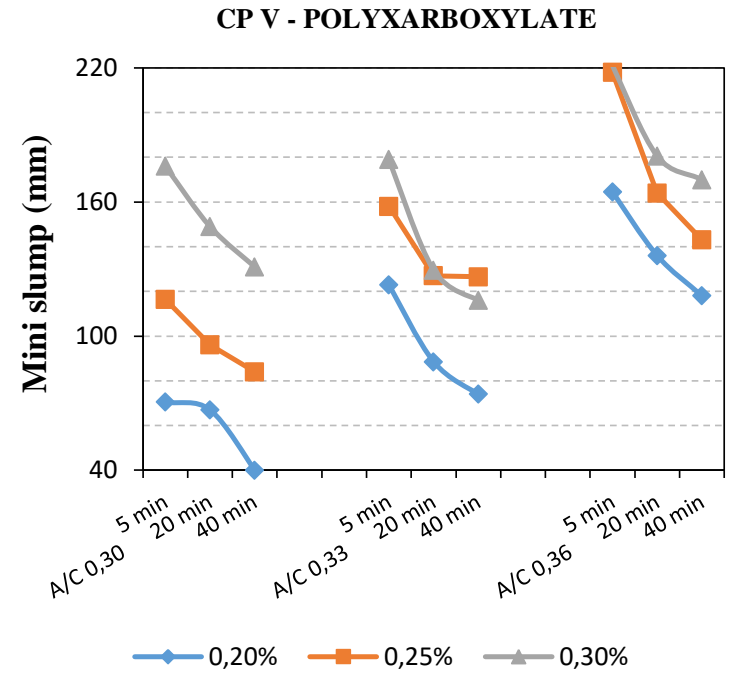

(b)

Figure 3: Mini slump test results for the pastes produced with polycarboxylate. (a) CP IV; (b) CPV-ARI.

Figure 4 shows the initial mini slump spread (i.e., immediately after the sample preparation) as a function of the w/c ratio, for the different combinations of admixture and cement types. In general, the spreading of the pastes increased with increasing the water reducer content. In the pastes produced with CP IV and lignosulfonate (Figure 4a), the mixes with contents below $2.50 \%$ of admixture presented an increase in the mini slump spread, while the mixes with higher contents $(2.75 \%$ and $3.0 \%)$ presented a decrease in the mini slump. This is because above a certain content, the addition of water reducer promotes an insignificant increase in flowability or even decreases it [20]. An excessive amount of non-adsorbed admixture molecules may result in cluster formation and hinder the flow of the paste [19]. This content is known as saturation point. It is worth mentioning that the employed levels are much higher than those indicated by the manufacturer (up to $1.00 \%$ ). This saturation is evidenced in pastes produced with CP V-ARI and lignosulfonate (Figure 4b), where the increase in admixture content showed a point from which the spread remained constant $(\mathrm{w} / \mathrm{c}=0.36)$ or decreased $(\mathrm{w} / \mathrm{c}=0.30$ and 0.33$)$, and this saturation content varied for each 
w/c. For pastes with CP IV and polycarboxylate (Figure 4c), the trend of increasing the spreading with increasing the admixture content was maintained, except for the $\mathrm{w} / \mathrm{c}=0.33 \mathrm{mix}$ where a mini slump decrease of $2 \%$ was found when the admixture content increased from $0.30 \%$ to $0.35 \%$ (attributed to the test variability). Finally, the pastes produced with CP V-ARI and polycarboxylate (Figure 4d) showed increased spreading with increasing admixture content for the mixtures $\mathrm{w} / \mathrm{c}=0.30$ and 0.33 , and their spreading evened at $0.30 \%$ of admixture. The w/c mixture $=0.36$ showed a very small spread gain (about $1 \%$ ) with the admixture content increasing from $0.25 \%$ to $0.30 \%$, being interpreted as admixture saturation point.

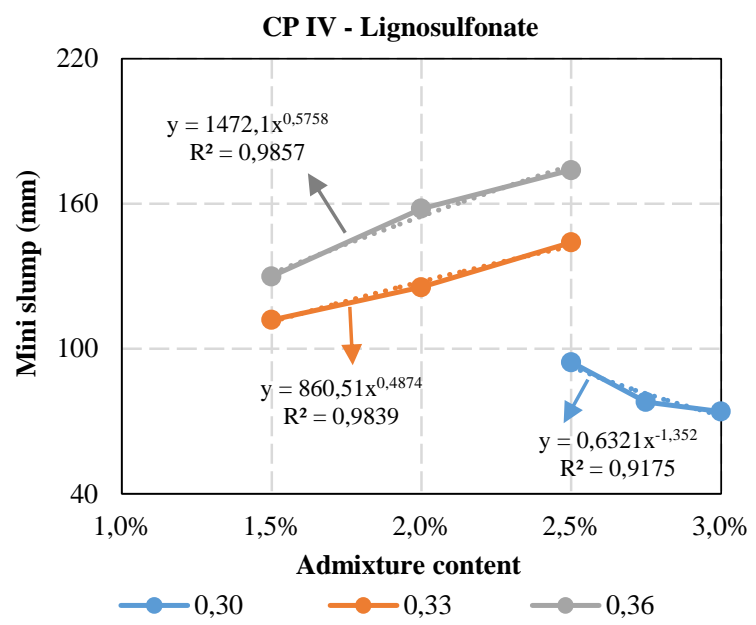

(a)

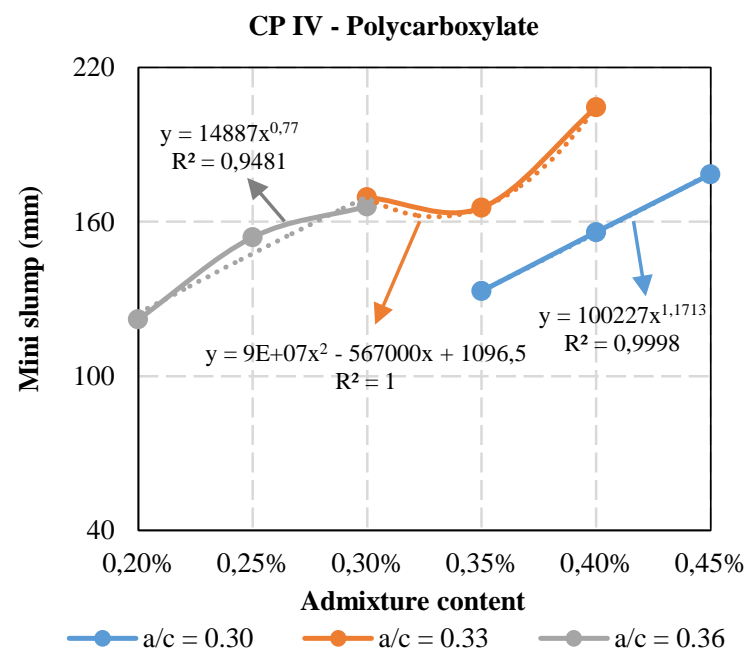

(c)

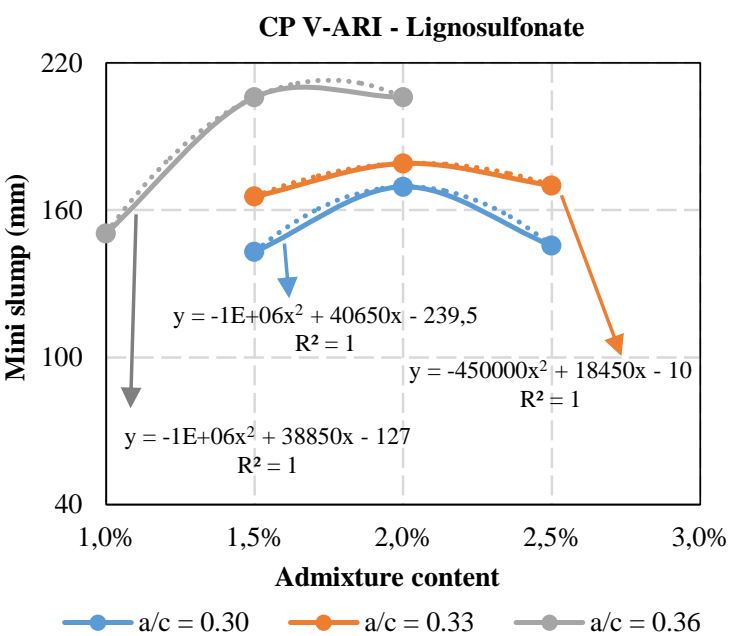

(b)

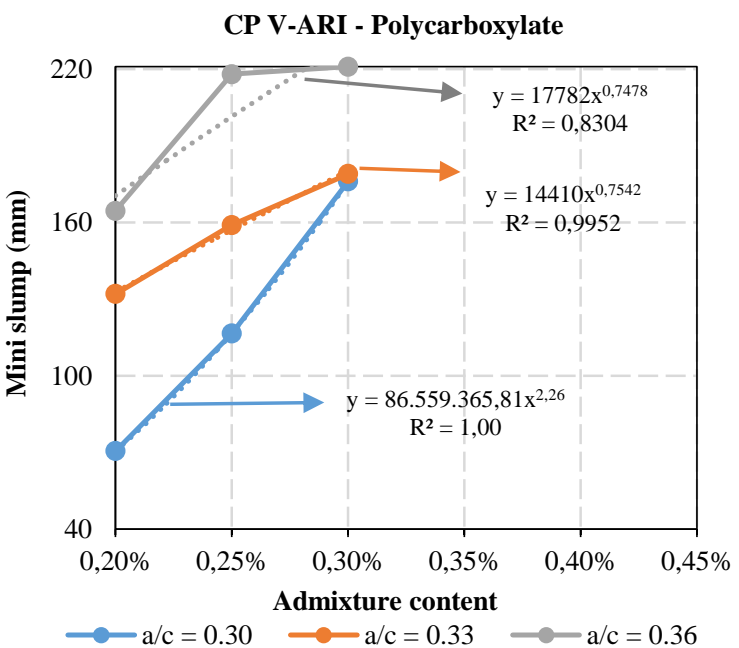

(d)

Figure 4: Mini slump results of the pastes as a function of the admixture content. (a) CP IV + Lignosulfonate; (b) CP VARI + Lignosulfonate; (c) CP IV + Polycarboxylate; (d) CP V-ARI + Polycarboxylate.

\subsection{Hardened state}

In this step, pastes produced with w/c of 0.36 and the different typed of cement and admixture were tested, with a fixed spreading of $130 \mathrm{~mm}$. In order to determine the water reducer content required for such spreading, interpolations were performed from the mini slump vs. admixture content curves, using the equations presented in Figure 4. Table 3 shows the admixture content used for each combination of cement and water reducer. The greater efficiency of the admixtures in CP V-ARI cement was evident, since it was required a $66 \%$ higher polyfunctional content was required and a $50 \%$ higher superplasticizer content in $\mathrm{CP}$ 
IV mixtures compared to CP V-ARI, to achieve the same spreading. This fact is justified by the previously presented reasons in item 3.1 - mainly due to cement-admixture compatibility.

Table 3. Admixture content required to achieve a mini slump spread of $130 \mathrm{~mm}$. Note: the results are shown in $\%$ by mass, over the cement mass.

\begin{tabular}{ccc}
\hline Cement & Polyfunctional & Superplasticizer \\
\hline CP IV & 1.48 & 0.21 \\
CP V - ARI & 0.89 & 0.14 \\
\hline
\end{tabular}

Figure 5 presents the compressive strength results. The error bars correspond to \pm 1 standard deviation. Two statistical analysis were performed here. Firstly, a spurious verification was conducted with $95 \%$ reliability, resulting in t-values of $1.480,1.049,1.049$ and 1.144 respectively for CP IV - Ligno, CP IV Poly, CP V-ARI - Ligno and CP V-ARI - Poly. These values were lower than the critical t-value of 1.500, indicating that no spurious values were found. Then, one-way ANOVA was conducted to check the existence of significant differences between the groups. The following comparisons were analyzed: (i) CP IV - Ligno vs. CP IV - Poly; (ii) CP V-ARI - Ligno vs. CP V-ARI - Poly; (iii) CP IV - Ligno vs. CP V-ARI - Ligno; (iv) CP IV - Poly vs. CP V-ARI - Poly. The p-values found were respectively $0.1307,0.1172,0.0449$ and 0.0137 (i.e., respective probabilities of influence of $86.93 \%, 88.28 \%, 95.51 \%$ and $98.63 \%$ ). Considering that, the comparisons (iii) and (iv) indicated that the pastes with CP V-ARI presented higher strengths compared with those containing CP IV (about 22\% higher), with 95-99\% probability. This is explained by the higher reactivity of $\mathrm{CP} \mathrm{V}$-ARI cement, since it had a mineral admixture content of less than 5\%, while CP IV cement had around $25 \%$ pozzolanic material (which only contributes to mechanical strength at latter ages). Furthermore, the comparisons (i) and (ii) indicated, with $87-88 \%$ probability, that the lignosulfonatecontaining pastes (CP IV - Ligno and CP V-ARI - Ligno) had a trend of higher strength (about 10\% higher) compared with those containing polycarboxylate (CP IV - Poly and CP V - Poly) for the respective cements. This behavior may be associated with the formation of the cementitious micro-structure. Polycarboxylatebased admixtures generally present high dispersing ability [5]. However, lignosulfonate-based admixtures tend to delay the cement hydration kinetics [17,21], which may result in a more organized formation of the micro-structure. It is worth remembering that the workability of the pastes was fixed (mini slump of 130 $\mathrm{mm}$ ), therefore the higher dispersing ability of the polycarboxylate-based admixtures may not lead to improvements in the hydration, compared to the lignosulfonate-based one.

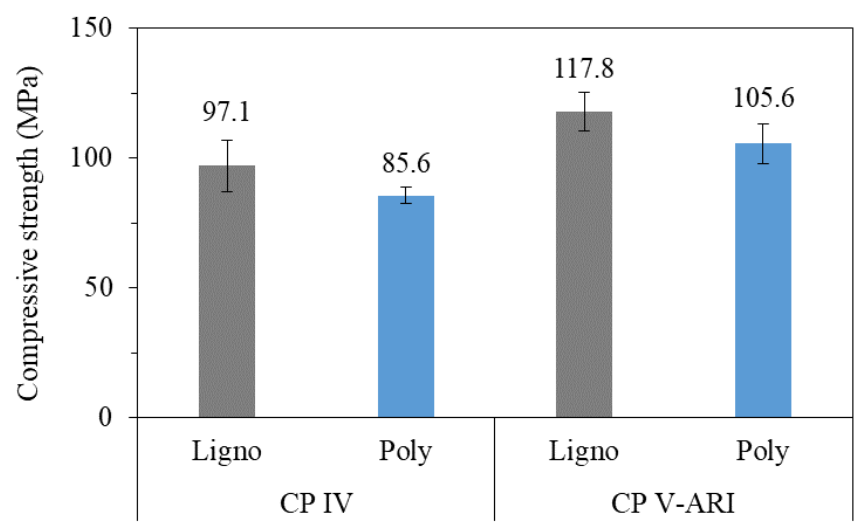

Figure 5: 28-day compressive strength of the pastes. Ligno: lignosulfonate; Poly: polycarboxylate.

\section{CONCLUSIONS}

This work investigated the workability maintenance of two water-reducing admixtures (a lignosulfonatebased and a polycarboxylate-based) in high-performance pastes (w/c ratio of $0.30,0.33$ and 0.36 ) produced with two types of Portland cement (CP IV and CP V - ARI). Based on the results presented in this paper, the following conclusions were established.

i) The measurements of the mini slump up to 40 minutes indicated a trend of workability reduction over 
time, as expected. However, some mixes showed equivalent or even higher spread after 20 and 40 minutes, compared to the initial values (immediately after mixing). Furthermore, there was a general trend of increasing the initial spread as the admixture content increased, which was also expected. However, admixture saturation was verified in some mixes, nor increasing neither decreasing the spread with increasing admixture content.

ii) The mixes that presented the best workability maintenance were those produced with $\mathrm{CP}$ IV + lignosulfonate, and with CP V-ARI + polycarboxylate. The presence of pozzolanic material in CP IV seems to be beneficial for the workability manteinance of lignosulfonate-based admixtures, while the higher clinker content of CP V-ARI may improve its compatibility with polycarboxylate.

iii) The pastes produced with CP V-ARI cement presented 28-day strengths about $22 \%$ higher than those with CP IV for both admixtures (with 95-99\% probability in ANOVA). In turn, the lignosulfonatecontaining pastes showed strengths about $10 \%$ higher than those produced with the polycarboxylate-based admixture (with $87-88 \%$ probability in ANOVA).

Overall, the set of results allows us to conclude that it is possible to obtain the same flowability for high-performance cement pastes with both lignosulfonate- and polycarboxylate-based admixtures. However, the workability mantainance highly depends on the combination of cement and admixture used. Furthermore, the great difference in the contents required by those types of admixture may affect the compressive strength of the material.

\section{AKNOWLEDGEMENTS}

The authors would like to thank CAPES (Higher Education Personnel Improvement Coordination), CNPq (processes 99999.008308/2014-04 and 99999.008307/2014-08) and FAPESC (Santa Catarina State Research Support Foundation) for the financial support for the work, and LabNANOTEC-UFSC (Laboratory of Nanotechnology Applications in Civil Construction) for offering the infrastructure to conduct the tests.

\section{REFERENCES}

[1] AÏTCIN, P.C., Cements of yesterday and today - concrete of tomorrow, Cem. Concr. Res. v. 30, pp. 1349-1359, 2000.

[2] MEHTA, P.K., MONTEIRO, P.J.M. Concrete: Microstructure, properties and materials, The McGrawHill Companies, 2015.

[3] COLLEPARDI, M. Admixtures used to enhance placing characteristics of concrete, Cem. Concr. Compos. v. 20, pp. 103-112, 1998.

[4] ROUSSEL, N., OVARLEZ, G., GARRAULT, S., et al.,The origins of thixotropy of fresh cement pastes, Cem. Concr. Res. v. 42, pp. 148-157, 2012.

[5] FLATT, R.J., SCHOBER, I. Superplasticizers and the rheology of concrete, in: Underst. Rheol. Concr., Woodhead Publishing, Cambridge, pp. 144-208, 2012.

[6] HARTMANN, C., ARA, J., SILVA, D., et al., Aditivos químicos para concretos e cimentos, in: G. Isaia (Ed.), Concreto Ciência e Tecnol., 1st ed., Ibracon, São Paulo, pp. 347-380, 2011.

[7] ALONSO, M.M., PALACIOS, M., PUERTAS, F. Compatibility between polycarboxylate-based admixtures and blended-cement pastes, Cem. Concr. Compos. v. 35, pp. 151-162, 2013.

[8] HABBABA, A., DAI, Z., PLANK, J. Formation of organo-mineral phases at early addition of superplasticizers: The role of alkali sulfates and C3A content, Cem. Concr. Res. v. 59, pp. 112-117, 2014.

[9] JOLICOEUR, C., SIMARD, M.A. Chemical admixture-cement interactions: Phenomenology and physico-chemical concepts, Cem. Concr. Compos. v. 20, pp. 87-101, 1998.

[10] DE MATOS, P.R., PRUDÊNCIO JR., L.R., PILAR, R., et al., Use of recycled water from mixer truck wash in concrete : Effect on the hydration, fresh and hardened properties, Constr. Build. Mater. v. 230, p. 116981, 2020.

[11] DE MELO, K.A., MARTINS, V.C., REPETTE, W.L. Estudo de compatibilidade cimento-aditivo redutor de água, Ambient. Construído. v. 9, pp. 45-56, 2009.

[12] PRINCE, W., ESPAGNE, M., AITCIN, P.C. Ettringite formation: A crucial step in cement superplasticizer compatibility, Cem. Concr. Res. v. 33, pp. 635-641, 2003.

[13] ZINGG, A., WINNEFELD, F., HOLZER, L. et al., Interaction of polycarboxylate-based superplasticizers with cements containing different C 3 A amounts, Cem. Concr. Compos. v. 31, pp. 153-162, 
2009.

[14] ABNT NBR 16697: Cimento Portland - Requisitos, pp. 12, 2018.

[15] KANTRO, D.L. Influence of water-reducing admixtures on properties of cement paste: a miniature slump test., Cem. Concr. Agreg. v. 2, pp. 95-102, 1980.

[16] ABNT NBR 7212: Cimento Portland - Determinação da resistência à compressão de corpos de prova cilíndricos, pp. 8, 2019.

[17] AÏTCIN, P., FLATT, R.J. Science and Technology of Concrete Admixtures, Woodhead Publishing Limited, 2016.

[18] SCHÖLER, A., LOTHENBACH, B., WINNEFELD, F. et al., Early hydration of SCM-blended Portland cements: A pore solution and isothermal calorimetry study, Cem. Concr. Res. v. 93, pp. 71-82, 2017.

[19] MATOS, P.R., OLIVEIRA, A.L., PELISSER, F., et al., Rheological behavior of Portland cement pastes and self-compacting concretes containing porcelain polishing residue, Constr. Build. Mater. v. 175, pp. 508$518,2018$.

[20] YEN, T., TANG, C., CHANG, C. et al., Flow behaviour of high strength high-performance concrete, Cem. Concr. Compos. v. 21, pp. 413-424, 1999.

[21] MATOS, P.R., JUNCKES, R., PRUDÊNCIO JR, L.R. Influência do uso de cinza volante na elevação adiabática de temperatura e resistência à compressão de concretos, Matéria (Rio Janeiro). e-12359, v. 24, 2019.

\section{ORCID}

Paulo Ricardo de Matos

https://orcid.org/0000-0002-3695-1356

Rafael Dors Sakata

https://orcid.org/0000-0002-7022-3846

Maiara Foiato

https://orcid.org/0000-0002-9951-177X

Wellington Longuini Repette

https://orcid.org/0000-0003-0697-2794

Philippe Jean Paul Gleize

https://orcid.org/0000-0003-4029-9345 